\title{
Incidental retinal vascular occlusions on hydroxychloroquine screening in patients with systemic lupus erythematosus
}

This article was published in the following Dove Press journal:

International Medical Case Reports Journal

28 May 2015

Number of times this article has been viewed

\author{
Asima Bajwa' \\ Gitanjali Khurana ${ }^{2}$ \\ Donald Kimpel ${ }^{2}$ \\ Ashvini K Reddy' \\ 'Department of Ophthalmology, \\ University of Virginia, Charlottesville, \\ VA, USA; ${ }^{2}$ Division of Clinical \\ Rheumatology, Department of Internal \\ Medicine, University of Virginia, \\ Charlottesville, VA, USA
}

Objective: The proportion of patients with systemic lupus erythematosus (SLE) who manifest retinal involvement increases many fold in patients with active systemic disease. The objective of this report is to stress upon the significance of comprehensive ophthalmic assessment of all SLE patients to prevent and manage blinding ocular manifestations of the disease.

Methods: Retrospective case review.

Results: Incidental retinal vascular complications seen in patients undergoing baseline hydroxychloroquine screening.

Conclusion: The purpose of comprehensive ophthalmic screening in SLE patients is twofold. It will aid in the diagnosis and treatment of blinding ocular complications of the disease and monitor hydroxychloroquine macular toxicity.

Keywords: systemic lupus erythematosus, hydroxychloroquine, retinal vein occlusion, retinal artery occlusion

\section{Introduction}

Systemic lupus erythematosus (SLE) is a multisystem autoimmune disease. Based on studies published over the span of three decades (1965-1995), the mean estimates for SLE incidence and prevalence, which vary widely, were $7.3 \%$ and $23.8 \%$ respectively. ${ }^{1-3}$

Assessment of SLE is often challenging due to multi-organ involvement and varied physical manifestations. Ocular lesions in SLE, such as cotton-wool spots, disk hyperemia, and white retinal patches were first reported by Bergmeister in 1929. ${ }^{4}$ While SLE can affect the ocular adnexa, and other areas in the central nervous system, the most common ocular manifestation in patients with SLE is dry eye syndrome. SLE can also cause severe vision loss as a result of vaso-occlusive insults to the retina or optic nerve. One of the most difficult assessments for physicians managing SLE patients is a thorough ocular examination. Table 1 summarizes the findings in 1,433 SLE patients as presented in a previous study. ${ }^{5}$

Hydroxychloroquine (HCQ) is one of the mainstay maintenance therapies for SLE patients, often used with other US Food and Drug Administration (FDA)-approved and non-approved treatments such as mycophenolate mofetil or azathioprine. HCQ can cause reversible, visually insignificant changes in the cornea (vortex keratopathy) and, more importantly, an irreversible sight-threatening maculopathy. Initial changes are subtle and often asymptomatic but can progress to a "bull's eye" maculopathy and even generalized atrophy of the retina and optic nerve. This complication is very rare, but may be potentially severe, thus requiring regular screening. Besides severe
Correspondence: Ashvini K Reddy

Department of Ophthalmology, University of Virginia, I 300 Jefferson Park Avenue, Charlottesville, VA 22908, USA

Tel + I 4342435890

Fax + I 4349245180

Email ash.vee.knee@gmail.com 
Table I Intraocular findings in I,433 patients with systemic lupus erythematosus*

\begin{tabular}{ll}
\hline Ocular findings & Patients, $\mathbf{n}(\%)$ \\
\hline Cotton-wool spots & $158(\mathrm{II} .02)$ \\
Retinal hemorrhages & $97(6.76)$ \\
Arterial narrowing & $87(6.07)$ \\
Papilledema & $13(0.91)$ \\
Retinal edema & $9(0.62)$ \\
Uveitis & $6(0.42)$ \\
\hline
\end{tabular}

Note: *Numbers and frequencies have been extrapolated from the given data in Gold et al. ${ }^{5}$

allergic reactions, retinal toxicity remains the only absolute contraindication to HCQ use in adults with SLE. ${ }^{6}$

\section{HCQ screening}

According to evidence-based, expert recommendations, longterm users of chloroquine or HCQ sulfate should undergo regular visits to eye care providers and diagnostic testing for maculopathy.

The American Academy of Ophthalmology has published revised screening guidelines for the monitoring of any patient taking chloroquine or HCQ. ${ }^{7}$ This examination includes slit lamp exam, dilated fundus exam, fundus photography, automated 10-2 visual fields, and one or more of the recommended objective tests which include spectral domain optical coherence tomography (SD OCT), fundus auto fluorescence, and multifocal electroretinogram. Additionally, if a patient is seen to have any retinal vascular complications, they may be assessed with fundus fluorescein angiogram (FA).

The rationale for the initial HCQ screening eye examination within the 1st year of therapy is to serve as a reference point and to rule out maculopathy which might be a contraindication to the use of this medication. However, patients with lupus are also at risk for other ocular changes. For that reason, we recommend an ocular exam for all SLE patients to identify any pre-existing abnormalities. As a practical matter, to establish compliance and identify any changes early, our rheumatology patients typically receive more frequent screening, on a 6-12 month schedule. We herein present our experience with incidental findings during HCQ screening for SLE patients.

\section{Case report \\ Patient I}

A 28-year-old African-American female with SLE and autoimmune lymphoproliferative syndrome was referred for baseline visual examination 3 months after starting HCQ $400 \mathrm{mg} /$ day. She was 64 inches in height and weighed $56.69 \mathrm{~kg}$. The calculated dose of HCQ was $7 \mathrm{mg} / \mathrm{kg}$ per day. The patient reported no vision changes since starting HCQ, but stated that she had always seen better out of her right eye. Her best-corrected visual acuity (BCVA) was 20/20 right eye (OD) and 20/25 left eye (OS) with normal pupil reactions, extra-ocular motility, and intraocular pressure (IOP). By confrontation method, she was noted to have a superior field defect OS.

A 30-degree automated visual field testing confirmed non-specific scattered changes OD, and a superior scotoma OS (Figure 1A). On dilated fundus exam, there was evidence of an old branch retinal vein occlusion (BRVO) with vascular collaterals OS (Figure 1B and C). FA confirmed non-perfusion inferotemporally and a low grade trickle of collaterals without macular leakage (Figure 1D and E). SD OCT revealed a normal foveal contour both eyes (OU) and inner retinal thinning OS in area of BRVO (Figure 1F).

The patient was diagnosed with BRVO OS and associated collateral formation without macular edema or neovascularization. There was no evidence of HCQ toxicity. The ocular findings were discussed with the patient along with the potential need for sectoral laser in the future. Given the chronicity of the ocular changes and likely remote occlusion, the patient opted to undergo observation. We recommended HCQ dose less than $6.5 \mathrm{mg} / \mathrm{kg}$ per day with follow-up every 3-4 months.

During her most recent follow-up, 3 months after the patient's initial diagnosis, the patient's vision was stable at 20/20 OD and 20/25 OS with a normal IOP. Ophthalmic examination and repeat OCT showed no further changes or progression.

\section{Patient 2}

A 20-year-old female with a history of SLE presented for HCQ screening. She had been on HCQ therapy for 5 months at $400 \mathrm{mg}$ per day. Her height was 68 inches and she weighed: $89.086 \mathrm{~kg}$. The calculated dose of HCQ was 4.5 $\mathrm{mg} / \mathrm{kg}$ per day. She noted visual loss OS for 5 months a few days prior to starting $\mathrm{HCQ}$, while she was hospitalized with SLE flare. Her BCVA was 20/20 OD and 1/200 OS with normal eye pressures and an afferent pupil defect OS. The OD examination and FA was unremarkable (Figure 2A and B). Dilated fundus examination OS showed marked vascular attenuation, macular exudates along with neovascularization of the disk (NVD), neovascularization peripherally/ elsewhere (NVE), and vitreous heme (Figure 2C). FA OS demonstrated diffuse vascular blockage, retinal nonperfusion, and leakage from NVE (Figure 2D). SD OCT of macula showed thinning of retinal layers OS with central macular thickness $227 \mu$ OD and $128 \mu$ OS (Figure 2E). Automated visual field testing revealed severe constriction of visual field OS (Figure 2F). 


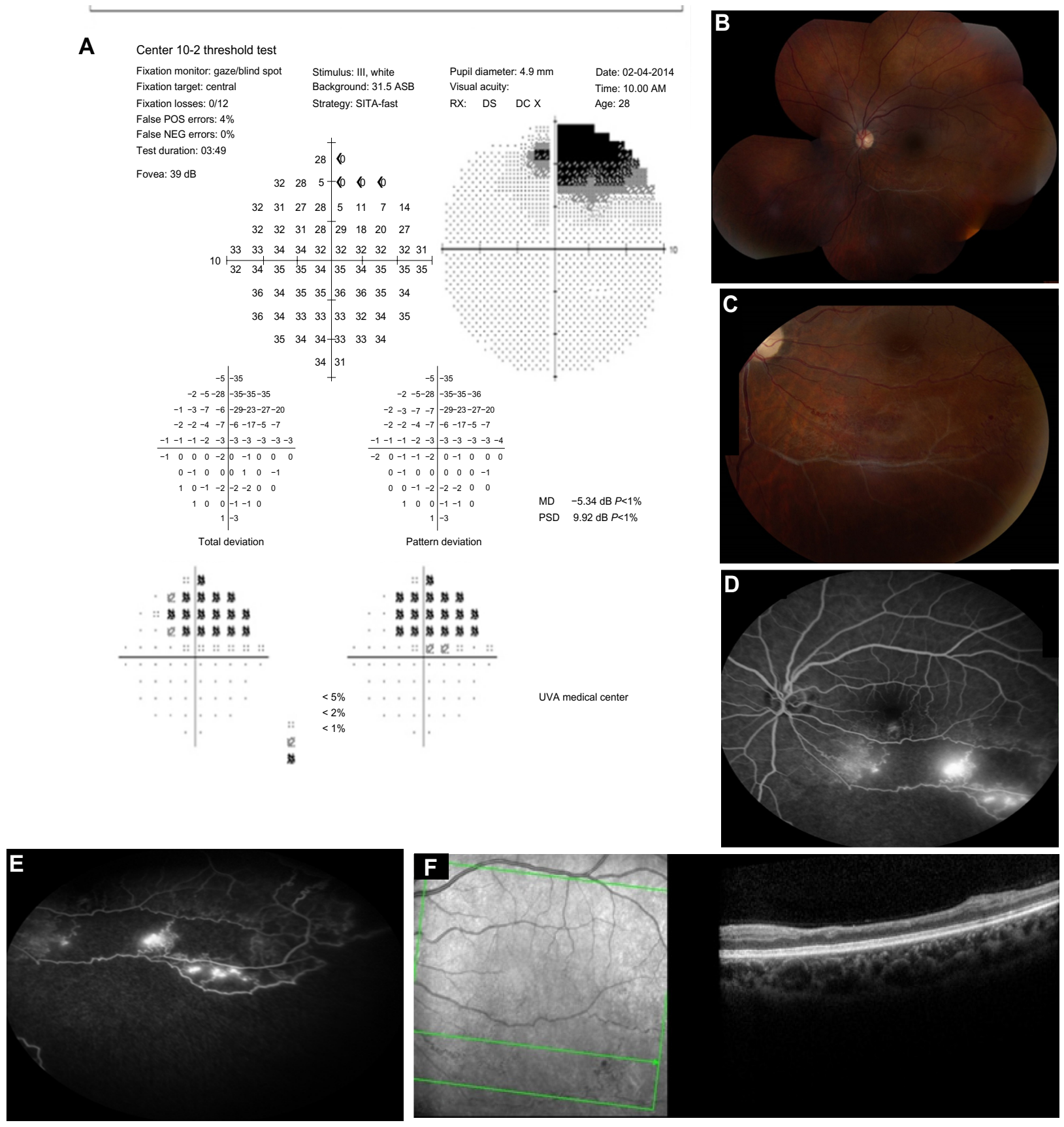

Figure I Visual field and fundus imaging of the patient with BRVO.

Notes: (A) Humphrey visual field 10-2 OS with superior field defect. (B) Wide-field color fundus montage OS showing inferotemporal BRVO. (C) Color fundus photograph OS showing inferotemporal BRVO, collaterals, and few dot blot hemorrhages. (D) FA OS with non-perfusion inferotemporally and hyperfluorescent leaky collaterals. (E) FA OS with hyperfluorescent collaterals. (F) SD OCT OS revealing inner retinal thinning OS in the area of BRVO.

Abbreviations: BRVO, branch retinal vein occlusion; FA, fluorescein angiogram; OD, right eye; OS, left eye; SD OCT, spectral domain optical coherence tomography.

The patient was diagnosed with central retinal artery occlusion/ophthalmic artery occlusion (CRAO/OAO) with neovascularization. She received pan-retinal photocoagulation and an intravitreal injection of $0.05 \mathrm{cc}(1.25 \mathrm{mg})$ bevacizumab OS. She was already on oral $81 \mathrm{mg}$ aspirin daily as she was positive for lupus anticoagulant factor.

On follow-up, she had BCVA 20/20 OD and counting finger OS with normal IOP. Fundus examination showed regression of NVD, macular exudates, and vascular attenuation with panretinal photocoagulation scars (Figure 2G). FA revealed resolving vascular leakage OS without macular edema (Figure 2H).

\section{Discussion}

Ocular involvement in SLE is well-described, but the ability of non-ophthalmologists to screen for retinal vascular disease is limited. Ideally, clinicians should conduct a fundoscopic 

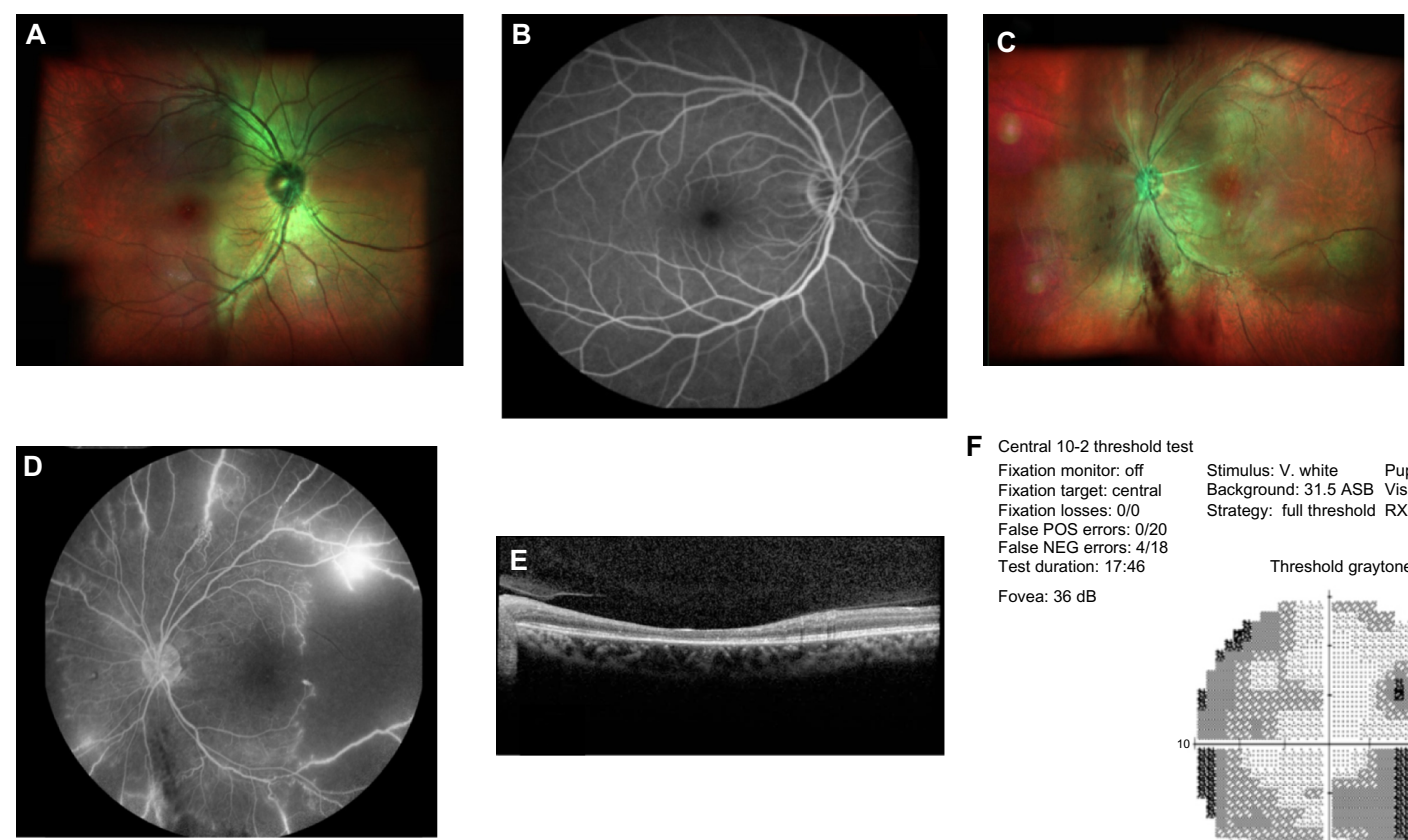

F Central 10-2 threshold test $\begin{array}{llll}\text { Fixation monitor: off } & \text { Stimulus: V. white } & \text { Pupil diameter: } & \text { Date: 03-24-2014 } \\ \text { Fixation target: central } & \text { Background: 31.5 ASB } & \text { Visual acuity: } & \text { Time: 12:04 PM }\end{array}$ Fixation losses: 0/0 False POS errors: $0 / 20$ False NEG errors: $4 / 18$ Test duration: 17:46 Fovea: $36 \mathrm{~dB}$
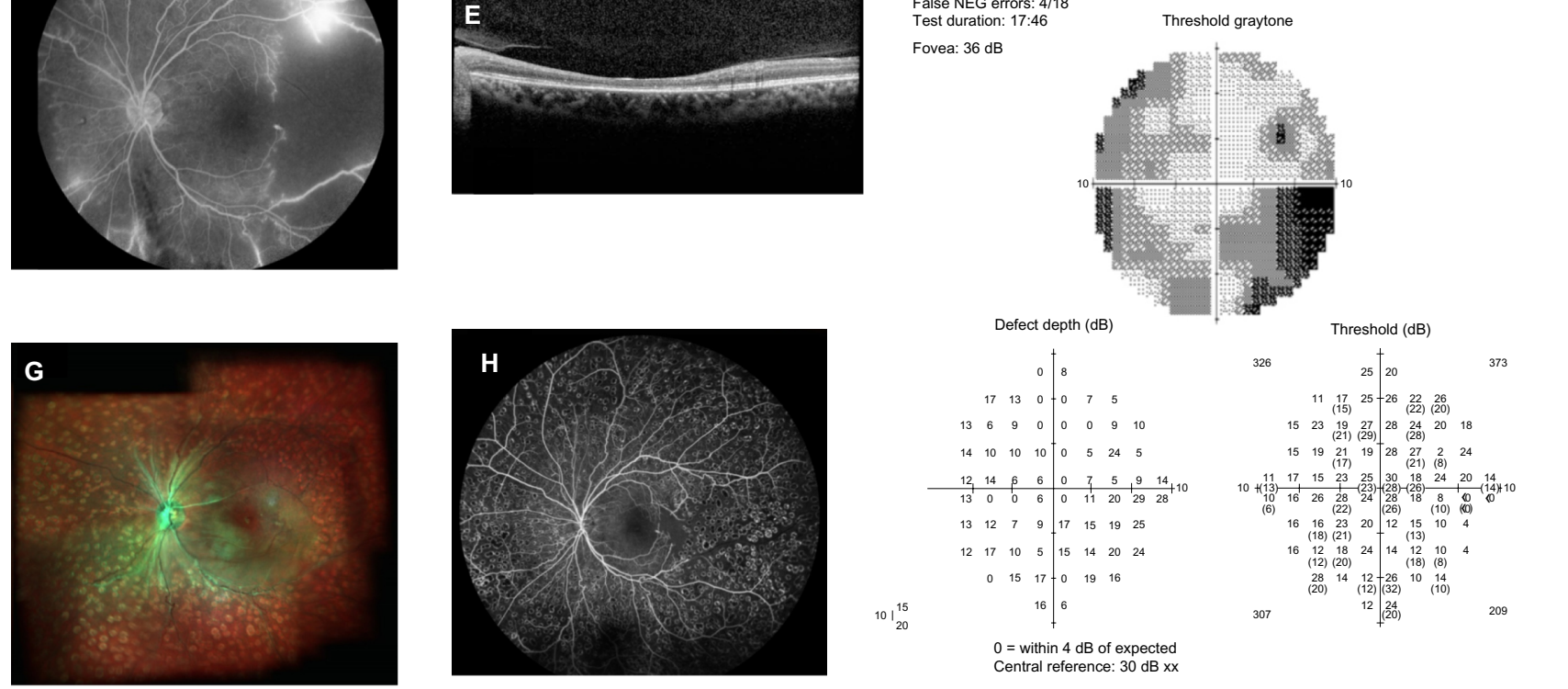

Figure 2 Fundus imaging and visual field analysis of the patient with ophthalmic artery occlusion.

Notes: (A) Multicolor fundus photo OD with normal optic disk, blood vessels, and retina. (B) FA OD with normal optic disk, blood vessels without macular leakage. (C) Multicolor fundus photo OS revealing vitreous hemorrhage, NVD, macular exudates, diffuse vascular attenuation, and atrophic retina. (D) Fluorescein angiogram OS showing diffuse vascular blockage, retinal non-perfusion, hyperfluorescent disk, and leakage from new vessels in the periphery. (E) SD OCT of macula OD showed thinning of inner retinal layers. (F) HVF I0-2 OS with severe constriction of visual field. (G) Multicolor fundus photo OS with regression of NVD and macular exudates following PRP. (H) FA OS with resolved vascular leakage and laser scarring.

Abbreviations: FA, Fluorescein angiogram; HVF, Humphrey visual field; NVD, neovascularization of the disk; OD, right eye; OS, left eye; PRP, pan-retinal photocoagulation; SD OCT, spectral domain optical coherence tomography.

examination to look for any vascular lesions. In common clinical practice, however, fundoscopic examination is often difficult to perform, and in any case does not permit a full view of the retina.

The cases discussed in this paper highlight the importance of scheduling SLE patients with an experienced ophthalmology team as more than HCQ toxicity may be diagnosed by the ophthalmologist and managed accordingly. Ocular vascular involvement may be an indication of active systemic disease which may require systemic anticoagulation and refined treatment.

Treatment for such findings would be selected based on disease activity; as such findings may represent old ocular damage which would not be amenable to systemic therapy.
For active systemic disease, therapy typically begins with systemic corticosteroids, and early introduction of intravenous cyclophosphamide, or oral mycophenolate mofetil. In the cases reported here the initial onset was remote, and disease activity was limited, so the primary therapy was HCQ. Additionally, since the second patient with CRAO had a positive test for lupus anticoagulant in her initial workup, she had been started on aspirin as prophylactic anticoagulant, before the first ophthalmologic exam. Because there had been no history of clot or miscarriage, and she reported distant onset of the CRAO/ $\mathrm{OAO}$, there was no indication for more aggressive anticoagulation or immunosuppression. In addition, if the patient develops neo-vascularization definitive treatment is retinal laser photocoagulation, which one of the patients received. 
The proportion of patients with SLE who manifest retinal involvement ranges from 3\% in well-controlled patients to $29 \%$ in patients with more active systemic disease. ${ }^{8-11}$

Retinal vascular changes correlate with the degree of systemic disease activity. Stafford-Brady et al reported that $88 \%$ of patients with retinopathy had active systemic disease and $73 \%$ had central nervous system involvement. ${ }^{12}$ Furthermore, they suggested that the patients with retinopathy had a lower overall rate of survival compared to individuals without retinopathy. Notably, severe vaso-occlusive retinopathy is a rare but well-described entity that is associated with widespread retinal capillary non-perfusion, multiple branch retinal artery occlusions, ocular neovascularization, vitreous hemorrhage, and significant resultant visual loss. ${ }^{13,14}$ (Table 2).

A study by Jabs et $\mathrm{al}^{11}$ showed that $55 \%$ of eyes in lupus patients with severe retinal vaso-occlusive disease suffered vision loss, often with visual acuity worse than $20 / 200$. The authors also observed more frequent central nervous system involvement in lupus patients with marked retinal vascular changes. Furthermore, central retinal vein or artery occlusions may occur, either independently or together, and may be unilateral or bilateral. ${ }^{15-17}$

While central retinal artery occlusion is rare, it is considered an ocular emergency and can cause permanent visual loss due to widespread retinal ischemia. It is often characterized by rapid, painless visual loss, a Marcus-Gunn afferent pupil defect, arterial attenuation, macular edema, and cherry red spot of fovea. ${ }^{18}$ Sudden visual loss with central retinal artery occlusion in a young patient should prompt the clinician to include SLE and other collagen diseases in the differential diagnosis.

Table 2 Signs of lupus retinopathy

I. Cotton-wool spots
2. Retinal hemorrhage: dot, blot, flame-shaped
3. Preretinal hemorrhage
4. Microaneurysms
5. Focal narrowing of retinal vasculature
6. Arterial occlusion with focal deposits
7. Central/branch retinal arterial occlusion with cherry red spot
8. Central/branch venous occlusion
9. Retinal neovascularization
10. Anterior segment ischemia
II. Vitreous hemorrhage
12. Traction retinal detachment
13. Neovascular or hemorrhagic glaucoma
14. Hypertensive changes (arteriolar narrowing, hard exudates, flame
hemorrhages, papilledema)
15. Optic disk vasculitis

Note: Reproduced from Bajwa A, Foster CS. Ocular Manifestations of Systemic Lupus Erythematosus, Review article. J Clin Cell Immunol. 2014;5:191. ${ }^{6}$
Central or BRVO is a less common manifestation of lupus retinopathy as the disease largely manifests as arteritis, but can still be a cause of permanent visual loss. ${ }^{19,20}$

The recently conducted National Ambulatory Medical Care Survey indicated that many patients at high risk for chloroquine or HCQ maculopathy are not undergoing routine monitoring for this serious adverse event. These findings underscore the need for physician education related to potentially devastating effects on the eye and an understanding of factors that may contribute to suboptimal adherence to expert guidelines. ${ }^{21}$

\section{Conclusion}

SLE patients are at a high risk of retinal vascular events that correlate with systemic disease activity. A comprehensive ophthalmological exam is recommended in all SLE patients, not only for HCQ screening, but also to ensure prompt diagnosis and management of blinding ocular complications related to the disease. Also, anti-platelet therapy may be considered for those at high risk for developing retinal vascular occlusion.

\section{Acknowledgment}

We are thankful to Rabia Aman for her valuable contribution to this paper with editing and collection of figures.

\section{Disclosure}

None of the authors have any conflicts of interest to disclose.

\section{References}

1. McCarty DJ, Manzi S, Medsger TA Jr, Ramsey-Goldman R, LaPorte RE, Kwoh CK. Incidence of systemic lupus erythematosus: race and gender differences. Arthritis Rheum. 1995;38(9):1260-1270.

2. Feldman CH, Hiraki LT, Liu J, et al. Epidemiology and sociodemographics of systemic lupus erythematosus and lupus nephritis among US adults with Medicaid coverage, 2000-2004. Arthritis Rheum. 2013;65(3):753-763.

3. Jacobson DL, Gange SJ, Rose NR, Graham NM. Epidemiology and estimated population burden of selected autoimmune diseases in the United States. Clin Immunol Immunopathol. 1997;84(3):223-243.

4. Bergmeister R. Uber primare and miliare Tuberkulose der Retina [About primary and miliary tuberculosis of the retina]. Wien Med Schnschr. 1929;79:1116-1119. German.

5. Gold DH, Morris DA, Henkind P. Ocular findings in systemic lupus erythematosus. Br J Ophthalmol. 1972;56(11):800-804.

6. Bajwa A, Foster CS. Ocular Manifestations of Systemic Lupus Erythematosus, Review article. J Clin Cell Immunol. 2014;5:191.

7. Marmor MF, Kellner U, Lai TY, et al. American Academy of Ophthalmology. Revised recommendations on screening for chloroquine and hydroxychloroquine retinopathy. Ophthalmology. 2011; 118(2):415-422.

8. Montehermoso A, Cervera R, Font J, et al. Association of antiphospholipid antibodies with retinal vascular disease in systemic lupus erythematosus. Semin Arthritis Rheum. 1999;28(5):326-332.

9. Klinkhoff AV, Beattie CW, Chalmers A. Retinopathy in systemic lupus erythematosus: relationship to disease activity. Arthritis Rheum. 1986;29(9):1152-1156. 
10. Ushiyama O, Ushiyama K, Koarada S, et al. Retinal disease in patients with systemic lupus erythematosus. Ann Rheum Dis. 2000;59(9): 705-708.

11. Jabs DA, Fine SL, Hochberg MC, Newman SA, Heiner GG, Stevens MB. Severe retinal vaso-occlusive disease in systemic lupus erythematosus. Arch Ophthalmol. 1986;104(4):558-563.

12. Stafford-Brady FJ, Urowitz MB, Gladman DD, Easterbrook M. Lupus retinopathy. Patterns, associations, and prognosis. Arthritis Rheum. 1988;31(9):1105-1110.

13. Au A, O'Day J. Review of severe vaso-occlusive retinopathy in systemic lupus erythematosus and the antiphospholipid syndrome: associations, visual outcomes, complications and treatment. Clin Experiment Ophthalmol. 2004;32(1):87-100.

14. Read RW, Chong LP, Rao NA. Occlusive retinal vasculitis associated with systemic lupus erythematosus. Arch Ophthalmol. 2000;118(4): 588-589.

15. Leibovitch I, Goldstein M, Loewenstein A, Barak A. Combined central retinal artery and vein occlusion in a patient with systemic lupus erythematosus. Rheumatology (Oxford). 2001;40(10):1195-1196.
16. Durukan AH, Akar Y, Bayraktar MZ, Dinc A, Sahin OF. Combined retinal artery and vein occlusion in a patient with systemic lupus erythematosus and antiphospholipid syndrome. Can J Ophthalmol. 2005;40(1):87-89.

17. Mendrinos E, Mavrakanas N, Kiel R, Pournaras CJ. Bilateral combined central retinal artery and vein occlusion in systemic lupus erythematosus resulting in complete blindness. Eye (Lond). 2009;23(5):1231-1232.

18. Varma DD, Cugati S, Lee AW, Chen CS. A review of central retinal artery occlusion: clinical presentation and management. Eye (Lond). 2013;27(6):688-697.

19. Silverman M, Lubeck MJ, Briney WG. Central retinal vein occlusion complicating systemic lupus erythematosus. Arthritis Rheum. 1987; 21(7):839-843.

20. Ellis CJ, Hamer DB, Hunt RW, et al. Medical Investigation of Retinal Vascular Occlusion. Br Med J. 1964;2(5417):1093-1098.

21. Sugai DY, Gustafson CJ, De Luca JF, et al. Trends in the outpatient medication management of lupus erythematosus in the United States. J Drugs Dermatol. 2014;13(5):545-552.
International Medical Case Reports Journal

\section{Publish your work in this journal}

The International Medical Case Reports Journal is an international, peer-reviewed open-access journal publishing original case reports from all medical specialties. Previously unpublished medical posters are also accepted relating to any area of clinical or preclinical science. Submissions should not normally exceed 2,000 words or

\section{Dovepress}

4 published pages including figures, diagrams and references. The manuscript management system is completely online and includes a very quick and fair peer-review system, which is all easy to use. Visit http://www.dovepress.com/testimonials.php to read real quotes from published authors.

Submit your manuscript here: http://www.dovepress.com/international-medical-case-reports-journal-journal 